\title{
A new TR $\beta$ mutation in resistance to thyroid hormone syndrome
}

\author{
Corina Neamțu, ${ }^{1}$ Claudiu Țupea, ${ }^{1}$ Diana Păun, ${ }^{1}$ Anca Hoisescu, ${ }^{1}$ Adina Ghemigian, ${ }^{1}$ \\ Samuel Refetoff, ${ }^{2}$ Chutintorn Sriphrapradang ${ }^{2}$
}

\author{
${ }^{1}$ National Institute of Endocrinology "C.I. Parhon", Bucharest, Romania; ${ }^{2}$ University of Chicago Medicine, IL, USA
}

\begin{abstract}
Thyroid hormones (TH) exert their actions by binding nuclear receptors alpha (TRa1) and beta (TRß1 and TRß2). Resistance to thyroid hormone (RTH) is a clinical syndrome with various clinical manifestations, its hallmark being decreased tissue sensitivity to the action of thyroid hormones. We report the case of a family harbouring a novel TRß mutation. Sequencing of the TRß gene revealed a single nucleotide substitution- $C$ to $G$ in codon 340: glutamine was replaced by glutamic acid. The clinical picture and biochemical and hormonal panel showed significant differences within the family, despite their sharing the same mutation. We also present the result of low-dose antithyroid treatment in one member of the family diagnosed with this rare condition.
\end{abstract}

Key words: Mutation, Resistance to thyroid hormone, Single nucleotide substitution, Thyroid hormone receptors

\section{INTRODUCTION}

Resistance to thyroid hormone (RTH) is a rare condition with subtle clinical manifestations, characterized by decreased sensitivity of the target tissues to thyroid hormone action. ${ }^{1}$ This leads to elevated levels of thyroid hormones (TH), accompanied by normal or high thyroid-stimulating hormone (TSH) values, in the absence of intercurrent illness or drug use. At the same time, TH feedback on TSH expression is preserved, but higher doses are required to

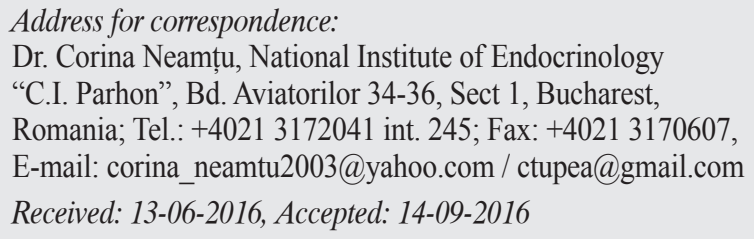

produce the expected response at both a pituitary and periphery level. The resistance is always partial and the underlying genetic defect is usually, but not always, a mutation in the TH receptor (TR) $\beta$ gene. ${ }^{2}$

Given the rarity of the syndrome, diagnosis may be overlooked and subtle abnormalities in lab tests may be considered technical mistakes. Patients are often clinically euthyroid, the most frequent clinical finding being goiter: when this is present, such signs and symptoms as tachycardia, hyperkinesia and emotional disturbances are quite common complaints. ${ }^{3,4}$

\section{CASE REPORT}

A 37-year old Caucasian woman, presenting the characteristics described above, sought medical at- 
tention at our Department for recurrent episodes of supraventricular tachycardia. In the absence of a specific cardiological condition, she was treated empirically with beta-blockers and propaphenone, but with limited efficacy. She was referred to our clinic for abnormal thyroid function tests: elevated free thyroxine (FT4) and normal TSH $[\mathrm{TSH}=1.1$ $\mu \mathrm{UI} / \mathrm{ml}(\mathrm{N}=0.5-4.5), \mathrm{FT} 4=31.8 \mathrm{pmol} / \mathrm{l},(\mathrm{N}=12-22)]$. The initial evaluation revealed normal intelligence, normal body mass index, a grade 2 nodular goiter but no signs and symptoms of hyperthyroidism except mild extrasystolic activity. The hormone panel was repeated using a different assay at another laboratory which confirmed the initial results. Thyroid ultrasound revealed a multinodular goiter (Figure 1), while scintigraphy showed diffuse increased uptake (Figure 2).

The differential diagnosis included two main entities, thyreotropinoma and RTH, for which dynamic testing was required. ${ }^{5}$

A thyrotropin-releasing hormone (TRH) test was performed by administrating a $200 \mu \mathrm{g}$ TRH iv bolus which led to an increase of the TSH level to 12.95 $\mu \mathrm{UI} / \mathrm{ml}$ at $30^{\prime}$. Further, the patient was given $87.5 \mu \mathrm{g} /$ day triiodothyronine (T3) orally for 10 days, which suppressed the TSH level to $0.05 \mu \mathrm{UI} / \mathrm{ml}$.

This lower dose of $\mathrm{T} 3$ was chosen to be given as the outcome of discussion of the patient's higher cardiac risk at a multidisciplinary team meeting. However, the suppression of TSH at a lower than the standard T3 total dose, together with the positive response of TRH, supported the suspicion of RTH.

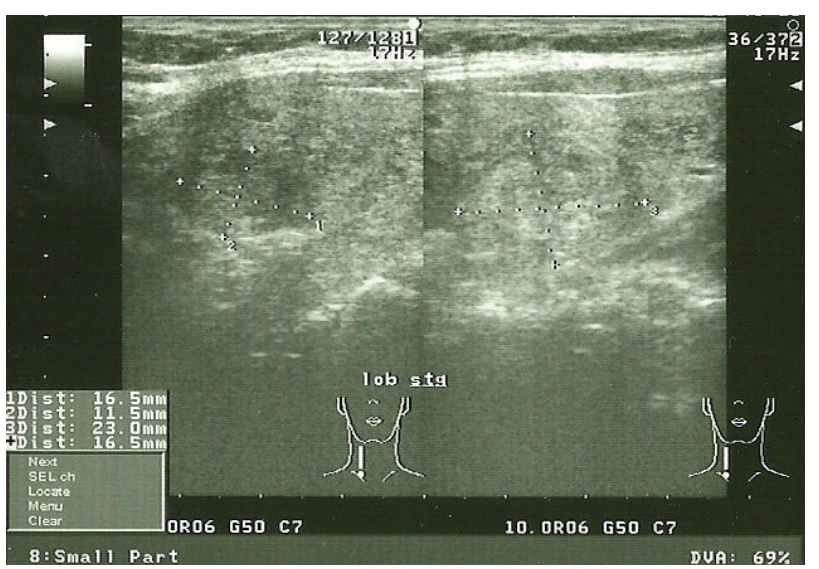

Figure 1. Nodule in left thyroid lobe.

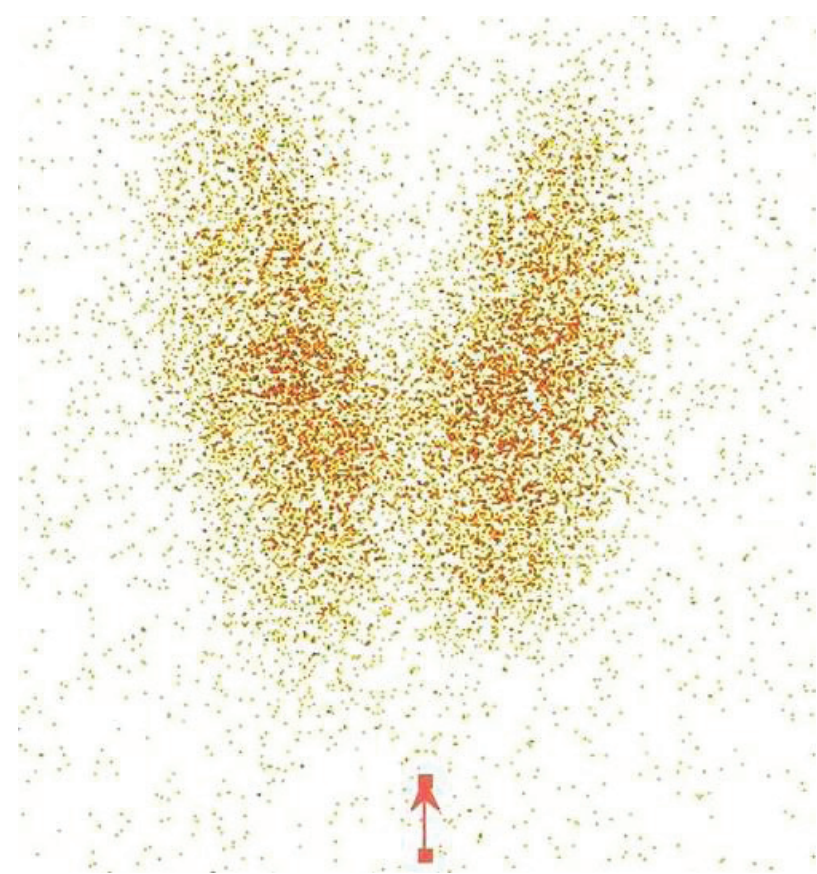

Figure 2. Increased uptake on thyroid scintigraphy.

The patient also underwent pituitary magnetic resonance imaging which showed a microadenoma of $4.3 / 4.1 / 3 \mathrm{~mm}$. The rest of her biochemical pituitary panel was within normal limits. Considering all of the results it was labeled as an incidentaloma.

Further tests were performed to establish the degree of peripheric resistance, and they showed a normal bone turnover (normal osteocalcin and alkaline phosphatase despite elevated T3 and T4) and also hepatic resistance demonstrated by the normal sex hormonebinding globulin (SHBG) level.

The immediate family was investigated and it was discovered that the patient's sister and niece both shared the hormonal pattern of elevated TH and normal TSH. The patient's only son had normal thyroid function tests.

We contacted Prof. S. Refetoff (University of Chicago) whose lab performed the genetic tests on this family.

\section{Thyroid function tests}

Total T4 (TT4), total T3 (TT3) and TSH were measured by chemiluminescence immunometric assays using the Elecsys Automated System (Roche Diagnostics, Indianapolis, IN, USA). Total rT3 (re- 
verse T3 or 3,3,5'-triiodothyronine) was measured by a commercial radioimmunoassay (RIA) (Adaltis Italia, Bologna, Italy) and thyroglobulin (TG) by an in-house RIA. ${ }^{6}$ The free $\mathrm{T}_{4}$ index $\left(\mathrm{FT}_{4} \mathrm{I}\right)$ and free $\mathrm{T}_{3}$ index $\left(\mathrm{FT}_{3} \mathrm{I}\right)$ were calculated as the product of the total serum concentrations of each iodothyronine and the normalized resin $\mathrm{T}_{4}$ uptake ratio. Antibodies (Ab) against TG and thyroperoxidase (TPO) were measured by passive hemaglutination (Fujirebio, Inc., Tokyo, Japan).

\section{Molecular analysis}

Genomic DNA was extracted from peripheral blood leukocytes using the QIAamp DNA Blood Mini Kit (QIAGEN, Valencia, CA, USA) in accordance with the manufacturer's instructions. For sequencing, coding regions (exons 7, 8, 9 and 10) and flanking introns of the TR $\beta$ gene were amplified using primers and a thermocycler setting similar to those previously described. ${ }^{7}$ The resulting polymerase chain reaction products were visualized on $1.8 \%$ agarose gel before direct automated sequencing.

\section{RESULTS}

Sequencing of the TR $\beta$ gene revealed a single nucleotide substitution- $C$ to $G$ in codon 340 , with glutamine replaced by glutamic acid. This precise mutation has not been reported to date, although a mutation $(\mathrm{Q} 340 \mathrm{H})$ in the same codon has been documented. ${ }^{8}$

The genetic tests confirmed the diagnosis and highlighted the variability of clinical findings and laboratory tests of this condition; our patient's sister and her 4-year old daughter were both asymptomatic, but the patient's niece showed a greater increase in T3 levels, which may be accounted for by decreasing thyroid hormone lev els with age. Moreover, the patient's sister had a thyroid autoimmune disease positive for TG Ab.

Results are illustrated in Figure 3.

We performed an in silico analysis using PolyPhen 2 software (Polymorphism Phenotyping version 2 http://genetics.bwh.harvard.edu/pph2/) to predict the
I

II

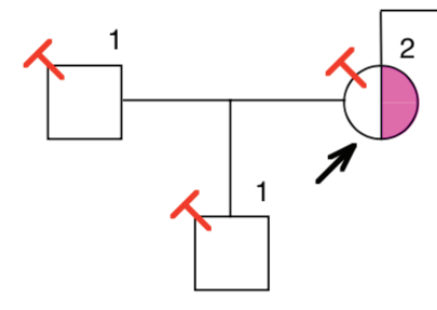

III

$\begin{array}{lcc} & \text { I-1 } & \text { II-1 } \\ \text { SAMPLE \# } & \text { R5225 } & \text { R5226 } \\ \text { Age (years) } & 43 & 12 \\ \text { TT4 } \mu \text { g/dl } & 7.1 & 5.2 \\ \text { TT3 } \mathrm{ng} / \mathrm{dl} & 99 & 139 \\ \text { TrT3 } \mathrm{ng} / \mathrm{dl} & 20.4 & 12.2 \\ \mathrm{FT} 4 \mathrm{l} & 8.7 & 6.2 \\ \mathrm{TSH} \mu \mathrm{U} / \mathrm{ml} & 3.8 & 3.4 \\ \mathrm{TG} & 11 & 6 \\ \text { TPO\&TG ab } & -/- & -/- \\ \text { Genotype } & \text { WT/WT } & \text { WT/WT }\end{array}$

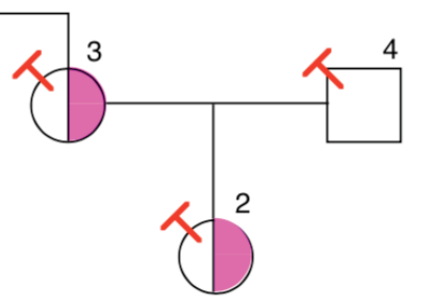

$\begin{array}{cccc}\text { I-2 } & \text { I-3 } & \text { II-2 } & \text { I-4 } \\ \text { R5224 } & \text { R5227 } & \text { R5229 } & \text { R5228 } \\ 38 & 33 & 5 & 39 \\ 15.2 & 12.1 & 25.0 & 7.1 \\ 173 & 139 & 426 & 112 \\ 46.3 & 40.6 & 69.6 & 24.2 \\ 17.5 & 13.4 & 26.8 & 8.7 \\ 2.5 & 3.4 & 8.2 & 1.4 \\ 29 & 22 & 39 & 9 \\ -/- & -/ 1: 320 & -/- & -/- \\ \text { WT/340E } & \text { WT/ 340E } & \text { WT/ 340E } & \text { WT/WT }\end{array}$

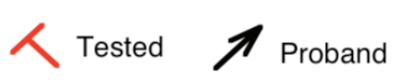

Figure 3. Family Mcon (January 2011).

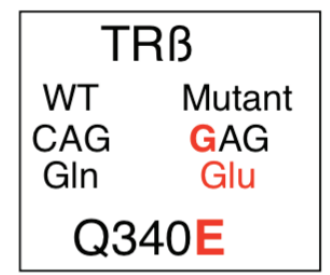

NORMAL RANGE

$$
\begin{gathered}
5-11.6 \\
90-180 \\
16-36 \\
6.0-10.5 \\
0.4-3.6 \\
1-30 \\
-/- \\
\text { WT/WT }
\end{gathered}
$$

Abnormal values in BOLD high in red and low in blue 
pathogenicity of the mutation. The result showed that it is probably damaging with a high score of 0.998 (sensitivity: 0.27, specificity: 0.99).

\section{DISCUSSION}

The family we studied fell into the broad category of patients with RTH harbouring a mutation in the TRß gene. ${ }^{9}$

RTH represents the main component of a larger group of genetic disorders which includes defects of the transmembrane transporter and of thyroid hormone metabolism. ${ }^{3}$ Recently, mutations of the SLC16A2 gene have been described, which encodes MCT8, a protein responsible for the transmembrane transport of TH and which is associated with the clinical picture of severe psychomotor disturbance ${ }^{10}$ and mutations of the SECISBP-2 gene implicated in the synthesis of deiodinases, altering the intracellular metabolism of $\mathrm{TH} .{ }^{11}$

Abnormalities of thyroid hormone-binding proteins (thyroxine-binding globulin and albumin) may resemble the laboratory pattern of $\mathrm{RTH}$, but using equilibrium dialysis to determine $\mathrm{T} 3$ and $\mathrm{T} 4$ levels $^{12}$ establishes the diagnosis.

The following refers to the most frequent form of $\mathrm{RTH}$, caused by TRß gene mutations.

The general features of RTH are elevated serum levels of free T4 and T3, normal or slightly increased TSH level that responds to RTH and increased doses of thyroid hormone and absence of the usual clinical consequences of TH excess and goiter. ${ }^{3,13}$ Depending on the symptoms, these patients have initially been classified as having selective pituitary resistance to $\mathrm{TH}$ if they appeared to be hypermetabolic, or as having generalized resistance to $\mathrm{TH}$ if the defect seemed to be compensated by the high levels of $\mathrm{TH}$, with no signs of hyperthyroidism. However, since individuals sharing the same mutation, even within the same family, seem to tolerate differently the elevation in thyroid hormone, it was concluded that the two forms are the result of subjectivity rather than being two separate entities. ${ }^{14}$

The defect in the RTH syndrome lies in the thyroid hormone receptor, which is a nuclear receptor encoded by two genes, designated alpha and beta, on chromosome 17 and 3. They each generate TR $\alpha$ and TRß molecules that have substantial structural and sequence similarities. The primary transcript for each gene can be alternatively spliced, generating different alpha and beta receptor isoforms. Of the four different thyroid hormone receptors (alpha-1, alpha-2, beta- 1 and beta- 2 ) only 3 are able to bind thyroid hormones. To a certain degree, TR $\beta$ and TR $\alpha$ are interchangeable, but some thyroid hormone effects are TR isoform specific. The receptors have specific organ distribution: TR $\alpha 1$ is widely expressed, especially in cardiac and skeletal muscles, while TR $\alpha 2$ is also widely expressed, but unable to bind hormone; TR $\beta 1$ is predominately expressed in brain, liver and kidney, while TR $\beta 2$ expression is limited to the hypothalamus and pituitary. ${ }^{15}$

There are three functional domains of the thyroid hormone receptor. A ligand-binding and dimerization domain at the carboxy-terminus, a DNA-binding domain that binds to the sequences of the DNA promoter known as the hormone response elements and a transactivation domain at the amino terminus that interacts with other transcription factors to form complexes that repress or activate transcription. Linking the DNA and ligand-binding domains is the hinge region that contains the signal for nuclear localization.

Mutations have been described almost exclusively in the beta isoform and the vast majority are point mutations. Only one family was reported to have a TRß gene deletion. ${ }^{16} \mathrm{~A}$ few years ago, a mutation was described in the TR $\alpha$ gene in association with a hypothyroid phenotype. ${ }^{17}$

All TRß gene mutations are localized in the carboxyl terminus of the TR $\beta$, mostly contained within three CpG-rich "hot spots", in the ligand-binding domain and adjacent hinge domain. Three mutational clusters have been identified with intervening cold regions. With the exception of the family with the TRß gene deletion, in all others, to the best of our knowledge, inheritance is autosomal dominant. Mutant TRß molecules are characterized by reduced affinity for T3, abnormal interaction with cofactors involved in thyroid hormone action and interference with the function of the wild type (WT) receptor. ${ }^{18}$ 
In a growing number of individuals, RTH occurs in the absence of mutations in the TR $\alpha$ or TR $\beta$ genes (non-TR-RTH).

The precise molecular etiology of these cases is not yet known, one of the hypotheses being a defect in one of the cofactors involved in the mediation of TH action. ${ }^{14}$

The more common form of RTH is characterized by minor defects in one allele of the TR $\beta$ gene, in contrast to individuals who lack one allele of the TRß that do not exhibit the RTH phenotype. These findings indicated that RTH is not simply the consequence of a reduced amount of a functional TR (haploinsufficiency) but is caused by the interference of the mutant TR with the function of the WT-TR (dominant negative effect). ${ }^{19}$

The variability of the RTH phenotype is explained both by individual tolerance to supraphysiological levels of thyroid hormone and by the distribution of receptor isoforms. The majority of untreated subjects maintain a normal metabolic state at the expense of high levels of $\mathrm{TH}$, but the degree of this compensation of tissue hyposensitivity to the hormone is also variable amongst individuals as well as in different tissues. As a consequence, clinical and laboratory evidence of TH deficiency and excess often coexist. ${ }^{2}$

Aside from diagnosis, another issue with regard to RTH is establishing a course of treatment or deciding if one is necessary at all. Considering the disturbing symptomatology in our patient despite the antiarrhythmic treatment, we decided in favour of a low-dose $(10 \mathrm{mg} / \mathrm{d})$ thiamazole therapy. Five months later her condition improved, allowing the cardiologist to stop propafenone and to reduce by half the beta-blocker dose, decreasing FT4 at the cost of a small increase in TSH that remained within normal limits.

Since the patient's sister and niece shared no abnormalities except for an abnormal antibody level, they will remain under our observation, especially for growth monitoring of the 4-year old girl. The absence of any clinical signs or symptoms in their case underlines the differences that may occur even within a family that shares the same mutation in the ligand-binding domain, allowing for variability of signal transduction due to both coexistence of the wild type receptor and intricate corepressor/coactivator mechanisms. ${ }^{20}$

Overall, RTH is a rare condition with only slightly more than 3,000 cases described, which may raise difficulties both in determining the diagnosis and in establishing an individualized management: studies show that up to one third of affected patients receive inappropriate treatments (thyroidectomy, radioiodine) before diagnosis is made, ${ }^{21}$ since genetic testing is relatively expensive and not easily accessible.

\section{ACKNOWLEDGMENTS}

We thank Professor Corin Badiu for his advice and for encouraging and helping us to publish this paper.

\section{CONFLICT OF INTEREST STATEMENT}

No competing financial interests exist.

\section{REFERENCES}

1. Refetoff S, DeWind LT, DeGroot LJ, 1967 Familial syndrome combining deaf-mutism, stippled epiphyses, goiter, and abnormally high PBI: possible target organ refractoriness to thyroid hormone. J Clin Endocrinol Metab 27: 279-294.

2. Refetoff S, Weiss RE, Usala SJ, 1993 The syndromes of resistance to thyroid hormone. Endocr Rev 14: 348-399.

3. Dumitrescu AM, Refetoff S, 2015 Impaired Sensitivity to Thyroid Hormone: Defects of Transport, Metabolism and Action. Thyroid Manager (thyroidmanager.org).

4. Amor AJ, Halperin I, Alfayate R, et al, 2014 Identification of four novel mutations in the thyroid hormone receptor- $\beta$ gene in 164 Spanish and 2 Greek patients with resistance to thyroid hormone. Hormones (Athens) 13: 74-78.

5. Vandalem JL, Pirens G, Hennen G, 1981 Familial inappropriate TSH secretion: evidence suggesting a dissociated pituitary resistance to T3 and T4. J Endocrinol Invest 4: 413-422.

6. Barsano CP, Skosey C, DeGroot LJ, et al, 1982 Serum thyroglobulin in the management of patients with thyroid cancer. Arch Intern Med 142: 763-767.

7. Adams M, Matthews C, Collingwood TN, Tone Y, Beck-Peccoz P, Chatterjee KK, 1994 Genetic analysis of 29 kindreds with generalized and pituitary resistance to thyroid hormone. Identification of thirteen novel mutations in the thyroid hormone receptor beta gene. J Clin Invest 94: 506-515.

8. Usala SJ, Menke JB, Watson TL, et al, 1991 A new point 
mutation in the 3,5,3'-triiodothyronine-binding domain of the c-erbAß thyroid hormone receptor is tightly linked to generalized resistance to thyroid hormone. J Clin Endocrinol Metab 72: 32-38.

9. Dumitrescu AM, Refetoff S, 2013 Reduced sensitivity to thyroid hormone: defects of transport, metabolism and action. In Werner \& Ingbar's The Thyroid: A Fundamental and Clinical Text. Braverman, LE, Cooper DS (eds), Wolters Kluver/Lippincott, Williams \& Wilkins Publications, Philadelphia, PA, pp; 845-873.

10. Boccone L, Mariotti S, Dessi V, Pruna D, Meloni A, Loudianos G, 2010 Allan-Herndon-Dudley syndrome (AHDS) caused by a novel SLC16A2 gene mutation showing severe neurologic features and unexpectedly low TRH-stimulated serum TSH. Eur J Med Genet 53: 392-395.

11. Dumitrescu AM, Liao XH, Abdullah MS, et al, 2005 Mutations in SECISBP2 result in abnormal thyroid hormone metabolism. Nat Genet 37: 1247-1252.

12. Cartwright D, O'Shea P, Rajanayagam O, et al, 2009 Familial dysalbuminemic hyperthyroxinemia: a persistent diagnostic challenge. Clin Chem 55: 1044-1046.

13. Kaplan MM, Swartz SL, Larsen PR, 1981 Partial peripheral resistance to thyroid hormone. Am J Med 70: 1115-1121.

14. Usala SJ, 1991 Molecular diagnosis and characterization of resistance to thyroid hormone syndromes. Thyroid 1: 361-367.

15. Bassett JH, Harvey CB, Williams GR, 2003 Mechanisms of thyroid hormone receptor-specific nuclear and extra nuclear actions. Mol Cell Endocrinol 213: 1-11.

16. Takeda K, Sakurai A, DeGroot LJ, Refetoff S, 1992 Recessive inheritance of thyroid hormone resistance caused by complete deletion of the protein-coding region of the thyroid hormone receptor- $\beta$ gene. J Clin Endocrinol Metab 74: 49-55.

17. Bochukova E, Schoenmakers N, Agostini M, et al, 2012 A Mutation in the Thyroid Hormone Receptor Alpha Gene. N Engl J Med 366: 243-249.

18. Yoh SM, Chatterjee VKK, Privalsky ML, 1997 Resistance to thyroid hormone syndrome manifests as an aberrant interaction between mutant $T_{3}$ receptor and transcriptional corepressor. Mol Endocrinol 11: 470-480.

19. Chatterjee VKK, Nagaya T, Madison LD, Datta S, Rantoumis A, Jameson JL, 1991 Thyroid hormone resistance syndrome. Inhibition of normal receptor function by mutant thyroid hormone receptors. J Clin Invest 87: 1977-1984.

20. Hayashi Y, Weiss RE, Sarne DH, et al, 1995 Do clinical manifestations of resistance to thyroid hormone correlate with the functional alteration of the corresponding mutant thyroid hormone- $\beta$ receptors? J Clin Endocrinol Metab 80: 3246-3256.

21. Bantle JP, Seeling S, Mariash CN, Ulstrom RA, Oppenheimer JH, 1982 Resistance to thyroid hormones: A disorder frequently confused with Graves' disease. Arch Intern Med 142: 1867-1871. 